\title{
Five Years Later: Assessing the Implementation of the Four Priorities of the Sendai Framework for Inclusion of People with Disabilities
}

\author{
DeeDee Bennett ${ }^{1}$
}

Published online: 20 April 2020

(C) The Author(s) 2020

\begin{abstract}
Efforts to reduce disaster risk around the world should purposefully consider the needs of potentially vulnerable populations, including people with disabilities. The Sendai Framework for Disaster Risk Reduction 2015-2030 (SFDRR) is one of the few global disaster-related frameworks with a focus on people with disabilities. The objective of this article is to assess the inclusion of people with disabilities in disaster risk reduction strategies worldwide since the establishment of SFDRR as gleaned from research. Several studies were reviewed to observe how the four priorities were implemented and operationalized in various countries to reduce the risk for people with disabilities. Findings indicate that initial applications of the SFDRR have compelled purposeful actions, but there is still room for improvement regarding people with disabilities. The results conclude that slight variations on the definitions of disaster or disability may increase marginalization. Three key themes emerged: (1) the intersectionality of disability with other dimensions of vulnerability warrants focused consideration; (2) enhanced disaster preparedness requires more attention in order to empower people with disabilities; and (3) negative cultural attitudes need to shift to enable purposeful inclusion of people with disabilities. Additional studies on the global investments made are encouraged to share lessons learned regarding the integration of people with disabilities.
\end{abstract}

DeeDee Bennett

dmbennett@albany.edu

1 College of Emergency Preparedness, Homeland Security and Cybersecurity, University at Albany, State University of New York, Albany, NY 12222, USA
Keywords Disaster resilience $\cdot$ Intersecting vulnerabilities · People with disabilities $\cdot$ Risk reduction $\cdot$ Sendai Framework

\section{Introduction}

The Sendai Framework for Disaster Risk Reduction 2015-2030 (SFDRR) is one of the first global frameworks that purposefully considers the needs of people with disabilities (Quaill et al. 2019). The SFDRR was adopted by United Nations Member States in 2015 and included four priorities for action to guide the development and implementation of policies on disaster risk reduction (DRR): (1) understanding disaster risk; (2) strengthening disaster risk governance; (3) investing in disaster risk reduction; and (4) enhancing disaster preparedness. Since adoption of the Sendai Framework, several studies have investigated the experiences of people with disabilities following disasters in several countries worldwide (Stough and Kang 2015; Maini et al. 2017; Mizutori 2018; Quaill et al. 2019).

Disasters have impacted nearly 60 million people in over 100 countries since the adoption of SFDRR in 2015 (Mizutori 2018). Although there are still academic discussions on the definition of "disaster," it is generally understood that disasters are not specific to any one hazard, nor are they completely uncontrollable (Perry 2018). In fact, most researchers acknowledge that social disruption is a key component (Perry 2018). In this article, the term will follow the Fritz (1961) definition, where a disaster is social and causes social disruption and creates the specific need for external help to assist in response and recovery. These disasters typically involve a hazard-natural or humaninduced-but are distinctly different from emergencies or relatively small crises. There is not, however, a clear 
definition of catastrophes. Quarantelli (2006) noted that catastrophes are larger than disasters, where the hazard destroys most of the infrastructure, external assistance is slow to arrive, and the impact has regional, national, or even international repercussions. Increased globalization and expanding populations that reside in high-risk habitation zones increase the possibility of hazard-causing catastrophes (Mizutori 2018). Therefore, throughout this article, the term disaster is used to encompass potentially catastrophic events. While the SFDRR provides the definition of a hazard, originally articulated in the Hyogo Framework for Action 2005-2015 (UNISDR 2005), it does not define a disaster.

In this article, "ability" is framed as a social construct, not a medical one. As a social construct, one's ability is correlated with external social factors, which fail to consider the needs of all people with varying abilities (Davis et al. 2013; Kelman and Stough 2015; Stough and Kelman 2018). This is different from the medical construct, which views disabilities as defects or sicknesses to be cured. Instead, the social model focuses on barriers and cultural attitudes that lead to exclusionary practices, which marginalize people with disabilities in terms of access, accommodation, education, employment, and voting, among others (Davis et al. 2013). This includes people who may not need additional support and with universal accessibility may be able to independently increase their resilience or become agents of change (Davis et al. 2013; Craig et al. 2019).

Nearly one billion people (15\% of the world population) are individuals with at least one disability (World Bank 2019). The social constructions of most societies increasingly lead to people with disabilities experiencing differential disaster impacts from the broader population. This perspective is related to theories on disaster vulnerability. Vulnerability theorists note that disasters are uniquely poised to exacerbate ongoing inequalities in any one society, thereby creating conditions for disproportionate impacts, especially among people with disabilities (Mileti 1999; Morrow 1999; Wisner et al. 2004; Cutter et al. 2006; Fordham 2011).

Vulnerable populations may have characteristics (as a group or individually) "that influence their capacity to anticipate, cope with, resist and recover from the impacts of disasters" (Wisner et al. 2004, p. 11). There are several characteristics and critical variables related to vulnerability including, disability, age, wealth, income, occupation, race and ethnicity, gender, health status, immigration status, religion, and so on (Wisner et al. 2004). These characteristics do not determine one's vulnerability status; instead, the variables mentioned may lead to an increased possibility of being vulnerable because of the impact of an extreme event. Additionally, vulnerability characteristics vary across different regions and nations; what may increase one's vulnerability in one country, may not in another. Internationally, the needs of people with disabilities regarding disaster risk reduction have been identified as significant.

This article investigates the implementation of disaster risk reduction strategies to purposefully incorporate consideration for people with disabilities globally since the inception of the SFDRR in 2015. The main concerns include individual and household preparedness (Pickering et al. 2017; Malpass et al. 2019), national and local level policies (Maini et al. 2017; Carby et al. 2018; Lunga et al. 2019; Quaill et al. 2019), and cultural attitudes (King et al. 2019; Lunga et al. 2019) toward individuals with different abilities. As one of the several population groups with the potential to be vulnerable during disasters, it is of the utmost importance that their needs are considered at every stage.

\section{Inclusion of People with Disabilities}

Among the nation-state disaster risk reduction plans publicly available, many have specific considerations for people with disabilities, though not all. A brief sketch of plans is listed in the table below by country.

While Table 1 is not an exhaustive list of countries discussed in this article nor of their disaster plans, it does showcase the variety of ways people with disabilities are considered at the national level. Although the Sendai Framework is not mentioned by name in all plans, countries may still have incorporated SFDRR. For example, the United States' position regarding SFDRR in 2015 was: "As we consider the Sendai Framework, we underscore the core principle of Disaster Risk Reduction, that each State has the primary responsibility for taking effective measures to reduce disaster risk, including for the protection of people on its territory, infrastructure, and other national assets" (Department of State 2015, p. 1). This is important, since the organizational structure of each country may be different and the roles for disaster risk reduction could be distributed. Similarly, the way in which each effort is executed may differ across local municipalities, just as their plans vary. In Vanuatu, for example, the provincial disaster plan of Sanma only mentions people with disabilities once and states: "Those with disabilities are also more vulnerable to hazards and future climate change" (Vanuatu 2017a, p. 25). Whereas the Tafea provincial disaster plan in Vanuatu mentions people with disabilities eight times with very specific considerations, such as focusing on disability-accessible and operational water and sanitation services to decrease the likelihood of diseases (Vanuatu 2017b). A more comprehensive study of one 
Table 1 Quick review of national level disaster plans in six countries

\begin{tabular}{|c|c|c|c|}
\hline & Title of plan (year) & Mention of SFDRR & $\begin{array}{l}\text { Mention of vulnerable populations or people } \\
\text { with disabilities }\end{array}$ \\
\hline Australia & $\begin{array}{l}\text { National Disaster Risk Reduction Framework } \\
\text { (Australia Government. Department of Home } \\
\text { Affairs 2018) }\end{array}$ & $\begin{array}{l}\text { Specifically mentioned in } \\
\text { the introductions and } \\
\text { organized by the four } \\
\text { priorities }\end{array}$ & $\begin{array}{l}\text { "Impacts are often felt disproportionately by } \\
\text { vulnerable or susceptible groups" (p. 5); } \\
\text { "Enhanced investment in vulnerable } \\
\text { communities" (p. 16) }\end{array}$ \\
\hline $\begin{array}{l}\text { New } \\
\quad \text { Zealand }\end{array}$ & $\begin{array}{l}\text { The guide to the National Civil Defence } \\
\text { Emergency Management Plan (New Zealand. } \\
\text { Ministry of Civil Defence \& Emergency } \\
\text { Management 2015) }\end{array}$ & $\begin{array}{l}\text { Specifically mentioned in } \\
\text { Sect. } 17 \text { Reduction (p. } 4 \text { ) }\end{array}$ & $\begin{array}{l}\text { Includes health or disability support/service } \\
\text { organizations as spontaneous volunteers } \\
\text { (Sect. } 4.2 \text { Volunteers) } \\
\text { Section } 1 \text { discusses the role of health and } \\
\text { disability services. All coordinated by the } \\
\text { ministry of health. } \\
\text { The target audiences for public information are } \\
\text { all people who are, or may be, directly or } \\
\text { indirectly affected by the emergency, including } \\
\text { culturally and linguistically diverse } \\
\text { communities and people with disabilities } \\
\text { (Sect. 28, p. 5) }\end{array}$ \\
\hline Philippines & $\begin{array}{l}\text { National Disaster Risk Reduction and } \\
\text { Management Plan (2011-2028) (Philippines. } \\
\text { National Disaster Risk Reduction and } \\
\text { Management Council 2011) }\end{array}$ & Not specifically mentioned & $\begin{array}{l}\text { "[...] it is equally important to preserve the } \\
\text { dignity of evacuees especially the elderly, } \\
\text { person with disabilities, women and children. } \\
\text { Gender roles and rights should always be } \\
\text { ensured" (p. 28); } \\
\text { "Gender mainstreaming is about the recognition, } \\
\text { acceptance, identification and addressing of the } \\
\text { different roles, needs, capacities and } \\
\text { vulnerabilities of men, women, children, } \\
\text { people with disabilities, older persons and other } \\
\text { groups" (p. 32) }\end{array}$ \\
\hline Thailand & $\begin{array}{l}\text { National Disaster Risk Reduction Plan (Thailand. } \\
\text { National Disaster Prevention and Mitigation } \\
\text { Committee 2015) }\end{array}$ & $\begin{array}{l}\text { Specifically noted in the } \\
\text { preface }\end{array}$ & $\begin{array}{l}\text { Disability noted in definition of a vulnerable } \\
\text { group (p. 130); } \\
\text { Webservice and mobile information was } \\
\text { mentioned for [vulnerable groups] (p. } 71 \text { ); } \\
\text { First priority for people with disabilities in } \\
\text { evacuation (p. 85); } \\
\text { Understanding of causal factors to vulnerability } \\
\text { in disaster risk reduction plans (p. 126) }\end{array}$ \\
\hline $\begin{array}{l}\text { United } \\
\text { States }\end{array}$ & $\begin{array}{l}\text { National Response Framework (United States. } \\
\text { Department of Homeland Security 2019) }\end{array}$ & Not specifically mentioned & $\begin{array}{l}\text { "Staff in EOCs [Emergency Operations Centers] } \\
\text { at all levels of government may also encourage } \\
\text { participation by [...] organizations } \\
\text { representing those with disabilities and others } \\
\text { with access and functional needs" (p. 17); } \\
\text { Coordinating integration of individuals with } \\
\text { disabilities, [...] needs into emergency } \\
\text { planning and response (p. 30); } \\
\text { "Order or recommend evacuations ensuring the } \\
\text { integration and inclusion of the requirements of } \\
\text { populations such as children; individuals with } \\
\text { disabilities and others with access and } \\
\text { functional needs [...]" (p. 31); } \\
\text { "Promoting physical accessibility, programmatic } \\
\text { inclusion, and effective communication for the } \\
\text { whole community, including individuals with } \\
\text { disabilities" (p. 38) }\end{array}$ \\
\hline
\end{tabular}


Table 1 continued

\begin{tabular}{|c|c|c|c|}
\hline & Title of plan (year) & Mention of SFDRR & $\begin{array}{l}\text { Mention of vulnerable populations or people } \\
\text { with disabilities }\end{array}$ \\
\hline Vanuatu & $\begin{array}{l}\text { National Cyclone Support Plan (2019-2020) } \\
\text { (Vanuatu. Ministry of Climate Change } \\
\text { Adaptation 2019) }\end{array}$ & Not specifically mentioned & $\begin{array}{l}\text { "Efforts should be made to ensure that } \\
\text { information is accessible to People Living } \\
\text { With Disability (PLWD) such as those that are } \\
\text { illiterate, have sight or hearing difficulties or } \\
\text { do not have access to radio or television" (p. } \\
\text { 16); } \\
\text { "The composition of a CDCCC [Community } \\
\text { Disaster \& Climate Change Committee] is to } \\
\text { be selected from community members } \\
\text { including [...] persons living with disabilities, } \\
\text { farmers and business people" (p. 8); } \\
\text { "Facilities and services provided for the } \\
\text { community must cater for People Living with } \\
\text { Disabilities (PLWD) and provide accessibility } \\
\text { for all [...]" (p. 19) }\end{array}$ \\
\hline
\end{tabular}

region in the United States, albeit a dated study, noted similar variations in how people with disabilities were included in disaster plans (Bennett 2010).

Although nation-state disaster risk reduction plans may not be equally comprehensive in the inclusion of SFDRR or people with disabilities, several researchers have investigated people with disabilities in various countries since the adoption of the SFDRR, including the countries listed in Table 1. The studies reviewed in this article were selected because they studied the impacts of disasters as it pertains to people with disabilities and mentioned the implementation of the SFDRR. The articles included were published between mid-2015 and mid-2019 and indexed in Proquest Social Science Collection offering full-text documents. Dissertations and articles that did not include mention to the SFDRR were omitted. Though a limited number of articles were identified, nearly 40, there were several key recommendations that can be gleaned from the findings and conclusions of the research conducted. Their studies about people with disabilities are presented across the four Sendai Framework priorities for action as they pertain to national and local policies.

\subsection{Understanding Disaster Risk}

Understanding disaster risk is to include all dimensions of vulnerability in the SFDRR. In general, this encompasses inclusion for people with disabilities, as well as people of varying ages, genders, and cultural backgrounds. However, within the "disability community," there are variations in needs. While the need for inclusive strategies for all vulnerability dimensions is important in disaster plans, often factors related to mental health, anxiety, or stress were not considered (Grant 2018). Other researchers cited a lack of inclusion around mental health issues (InterAgency Standing Committee 2015; Stough and Kelman 2018), considerations for the deaf population (Pickering et al. 2017; Bennett et al. 2018; Craig et al. 2019), and with regards to children with disasters (Ronoh et al. 2015; Stough et al. 2017).

Building capacity among individuals at risk during disasters may aid in lessening their vulnerability, although many scholars found that not emphasizing human, social, and economic capital can thwart efforts. For example, children with general awareness and understanding of potential hazards in Christchurch, New Zealand may have an increased capacity to anticipate and cope with following the impact of an extreme event (Ronoh et al. 2015). Similarly, allowing for independence among people with disabilities in shelters may increase their capacity; however, sheltering for people with disabilities is an under-researched area in Australia (Malpass et al. 2019). Quaill et al. (2019) also found that communications and sheltering information were often inaccessible, leading to people with disabilities enduring more difficulties during recovery. All of these findings highlight the need to develop purposeful guidelines for the collection of indicators to support the SFDRR priorities; however, this would require detailed thinking, time, and consultation with a diverse range of stakeholders (Maini et al. 2017).

Moving beyond an understanding of all the dimensions of vulnerability to "all-of-society engagement and 
partnership" may be the way to move forward (Gray 2017). Accomplishing this type of collaboration in "an inclusive, accessible, and non-discriminatory manner would help to ensure no one is left behind" (Gray 2017, p. 1452). Furthermore, moving from just understanding to a targeted engagement and partnership would ensure that policymakers and future practices would be developed (at least in part) by people with disabilities. This leads to the importance of social capital and to movement beyond perceived social support to a realized membership and partnership among policymakers, practitioners, and individuals from the disability community. Several researchers have previously noted that the need for inclusion starts at the planning and development stage (Bennett et al. 2017; Castro et al. 2017; Maini et al. 2017; Carby et al. 2018; Lunga et al. 2019).

\subsection{Strengthening Disaster Risk Governance}

In the last 5 years, there is evidence of a lack of inclusion among people with disabilities when plans are developed or in receiving guidance (Ronoh et al. 2015; Ronoh 2017; Lunga et al. 2019). More importantly, evidence of negative attitudes and discrimination for people with disabilities are often culturally engrained (King et al. 2019; Lunga et al. 2019). Furthermore, some researchers have noted that the definition of a disaster is often unclear (Maini et al. 2017; Lunga et al. 2019), leading to further marginalization during extreme events.

The SFDRR establishes that people with disabilities and disability organizations should be included as legitimate stakeholders (Stough and Kang 2015). Across different geographical regions, researchers have noticed that participation among people with disabilities has not occurred during the development of disaster risk reduction plans in recent years. The factors which may assist in building capacity among people with disabilities have not been included in several disaster risk reduction activities in Queensland (Quaill et al. 2019). Similarly, ability and ageappropriate resources have not been adequately developed in New Zealand (Ronoh et al. 2015; Ronoh 2017; and see also Saunders et al. 2020). Furthermore, in Zimbabwe, researchers noticed that people with disabilities were not key collaborators during the development of disaster risk reduction measures (Lunga et al. 2019).

The lack of inclusion may be the result of cultural biases and discrimination concerning people with disabilities. Lunga et al. (2019) found variation in how disability was viewed in Zimbabwe or even a belief that a person with a disability has a purpose. King et al. (2019, p. 459) similarly noted that "raising awareness, combatting negative attitudes, and addressing discrimination would reduce vulnerability and result in better outcomes during disasters for all people in the Solomon Islands, inclusive of people with disabilities." Each of these studies points to potential threats to realized increase in resilience for people with disabilities at the individual and institutional levels.

Inclusion in disaster planning may be hindered by discrimination or by a lack of definition of disaster, or both. Researchers noted that many "lacked the understanding of what constitutes a disaster to such an extent that even disability is regarded as a disaster (Lunga et al. 2019, p. 1)." Maini et al. (2017) also noted that there is a lack of a universal classification of disasters contributing to health data recording being haphazard and unstandardized (see also Wright et al. 2020). While this article identifies a definition of a disaster, the SFDRR only focuses on the hazards that may cause disasters. The distinction may cause some misunderstanding.

\subsection{Investing in Disaster Risk Reduction}

Nearly all research on people with disabilities and disaster risk reduction mentions a need for investment in data collection and policy development to decrease vulnerability (Ronoh et al. 2015; Ronoh 2017; Twigg et al. 2018; King et al. 2019; Quaill et al. 2019). However, there are only a few that mention actual ongoing investments (Baker et al. 2017; Carby et al. 2018). Ronoh et al. (2015) stated that progress in the investment of disaster risk reduction strategies is imperative to empowerment and can be achieved by a focus on collaboration, coordination, and consistent with relevant stakeholders at-the-table. A similar sentiment was found by Quaill et al. (2019), "a collaborative and coordinated approach driven by disability-inclusive policy at all levels of government is needed." However, the collaboration and coordination must include an understanding of the variability in disability types (Grant 2018), the inclusion of people with disabilities during development (King et al. 2019), and the consideration of the cultural attitudes towards disability (Twigg et al. 2018). Again, this focuses on social capital; however, there should be some consideration on how economic capital may factor into the ability for people with disabilities to make an impact.

In at least two instances, Vanuatu and Jamaica, there are examined efforts ongoing to invest in disaster risk reduction activities. In recommendations for humanitarian leaders, researchers found a need for reliable quantitative data on the experiences of people with disabilities in Vanuatu (Baker et al. 2017). The report noted that in response to Tropical Cyclone Pam disability organizations worked with key government organizations for a needs assessment in one affected island (Tanna) with regards to disability to collect real data (Baker et al. 2017). Similarly, Carby et al. (2018) mentioned that Jamaica has developed a 
national policy and is beginning to enact legislation to understand and recognize the rights of people with disabilities.

\subsection{Enhancing Disaster Preparedness}

Research and reports over the last 5 years not only have highlighted the need to empower people with disabilities (Phibbs et al. 2016; Castro et al. 2017; Quaill et al. 2019), but also note that inclusivity has not been fully achieved by all (Carby et al. 2018; Carby and Ferguson 2018; Grant 2018; King et al. 2019). People with disabilities, disability organizations, and care providers can and should contribute to disaster risk reduction and mitigation (Bennett et al. 2017; Castro et al. 2017; Gray 2017; Maini et al. 2017; Carby and Ferguson 2018; Grant 2018; Lunga et al. 2019). Their risk perception may present new issues and, thus, deserves more attention from researchers, disaster practitioners, and policymakers (Castro et al. 2017); for instance, "Disability support groups could provide a forum for people with disabilities to share their cyclone knowledge and exchange ideas for managing wellbeing with each other to minimize vulnerability and enhance personal resilience" (Quaill et al. 2019, p. 64).

Perhaps there are additional indicators to consider. Phibbs et al. (2016) presented seven concepts that resonate with contemporary public health practice that would assist with enhancing disaster preparedness, which include the social determinants of health and inequality and inequity, among others. These studies identify the potential for a real increase in social and human capital for people with disabilities; furthermore, some studies showed that by providing a voice to the voiceless, attitudes shifted towards inclusiveness (Ronoh 2017).

Carby et al. (2018) indicated that disability inclusiveness had not been achieved by many government entities concerning the full participation of people with disabilities in society. Additionally, there are indications that compounding vulnerabilities are not often addressed. Children with disabilities are often neglected in disaster risk reduction initiatives or the development of such efforts (Ronoh et al. 2015; Kabir 2016; Stough et al. 2017).

\section{Disaster Risk Reduction and People with Disabilities}

Although there are valuable lessons to be discussed concerning elements that factor into disaster resilience (Kendra et al. 2018), there were three significant findings across the board. First, definitions matter because they affect how and when people with disabilities are included. The definitions used in this article orient the reader to the social construct of disability. Additionally, what constitutes a disaster was also purposefully defined due to potential misinterpretations, which may lead to exclusionary policy. Second, considering intersectionality ${ }^{1}$ is essential. While we have multiple dimensions of vulnerability, individuals are not static and often cannot be singularly grouped. Third, people with disabilities are not a homogenous group of individuals. The variety of types of abilities within this "community" causes differential disparities and impacts.

\subsection{Definitions and Inclusion}

Since the establishment of the Sendai Framework, researchers have highlighted the variability in how disability is defined and the impacts of the definition to specific inclusion and resilience initiatives. Lunga et al. (2019) held interviews and focus groups of people with disabilities following weather-related hazards and disasters in Zimbabwe and found that people with disabilities were not included in the formulation of disaster risk reduction measures. Additionally, definitions varied regarding the terms "disability" and "disaster." When disability is viewed as a social construct, people with disabilities can be considered capable of taking steps to reduce their vulnerability. In the Solomon Islands, researchers noticed that "underlying societal attitudes and discrimination toward PWD impacted on their inclusion in the different phases of the disaster management cycle" (King et al. 2019, p. 464), and was likely caused by a varying definition of disability. Craig and colleagues reviewed considerations for the deaf community in the Philippines, Cambodia, and Thailand, and found some viewed people with disabilities through a medical model lens, as objects of care, or as a charity (Craig et al. 2019). Ronoh et al. (2015) stated that there was a lack of clarity and understanding of the term "disability," and, thus, it was inconsistently articulated. Concerns around the inconsistency have been ongoing for some time (Kailes and Enders 2007). The variation in how disability is defined can cause differences in how they are included. It can begin to explain exclusion and marginalization in disaster-related activities (Ronoh et al. 2015;

\footnotetext{
1 The term coined in the late $1980 \mathrm{~s}$, is attributed to Kimberlé Crenshaw and is often used in sociology and social studies to explain the multilayer complexity of individual experiences specifically with regards to inequity. Per scholars Collins and Bilge (2016), the term emphasizes that inequities often cannot be fully understood by one single dimension of social division. While initially focused on race, gender, and class, the term can include other social divisions that make up the true lived experience of individuals in society such as ethnicity, ability, or religion. Disaster research focused on persons with disabilities may not include compounding vulnerabilities or additional barriers they may face, such as being a child with disability, women with disability, or a little girl with disability.
} 
Stough and Kelman 2018; King et al. 2019) and variability in terms used to address people with disabilities in planning documents (Kailes and Enders 2007; Priestley and Hemingway 2007).

The SFDRR may have a variable rate of inclusion for people with disabilities globally. Several researchers and reports have noticed a variation in the integration of people with disabilities. For Tropical Cyclone Pam, "where the needs of people with disabilities were identified, these were not prioritized during the response and some people with disabilities missed out on distributions altogether" (Baker et al. 2017, p. 1). Twigg et al. (2018) found that even though the considerations for people with disabilities in disasters are increasingly addressed, barriers still exist. Similarly, Castro et al. (2017) noticed new issues presented in Chile among people with disabilities and risk perception. Also Carby et al. (2018) observed that in Jamaica, disability inclusiveness had not been achieved in disaster risk reduction policy implementation.

\subsection{Intersectionality Needs to be Addressed}

Several characteristics influence vulnerability, and individuals may be members of more than one group at risk during a disaster. This intersectionality refers to being a person with a disability and also a member of another dimension of potential vulnerability such as a child, older adult, member of a marginalized ethnic group, or gender. It is the interconnected characteristics that may lead to further marginalization, discrimination, or difficulties during disasters. Concerning children, Ronoh et al. (2015) noted that the needs of children with disabilities had been largely overlooked following the earthquakes in 2010 and 2011 at Christchurch, New Zealand. Similarly, Kabir (2016) suggested that children with disabilities must be included in a separate policy-based framework based on investigating policies in Bangladesh.

There are potential concerns around older adults with and without disabilities. Akanuma et al. (2016) found that news reports about disasters were difficult for both sets of people to understand, based on their research in Japan. Additionally, the Mt. Kenya Times (2016) reported World Health Organization data noting that although $15 \%$ of the global population is made of people with at least one disability and that nearly $12.5 \%$ of people are over 60 years of age, both communities have been underserved in humanitarian response. Older adults with a disability are potentially further marginalized during disaster response because their crosscutting concerns are not fully considered.

Similar considerations are related to the intersection of health and disability. Gray (2017) pointed out the prospect of "triple jeopardy" compounding the social determinants of health, disaster vulnerability, and considerations with and for people with morbid obesity. Meanwhile, the measurement of health-related indicators is challenging by itself (Maini et al. 2017). The lack of a universal classification of disasters also means that the recording of health data in disasters is not standardized (Maini et al. 2017; Lunga et al. 2019).

While the reviewed studies focused on age and health, potentially compounding vulnerability for people with disabilities, other factors may also increase disaster risk (World Bank Group 2017). For example, studies have previously focused on gender and gender identity, ethnic and cultural background, religion, and socioeconomic status as contributors to increased vulnerability to disasters (DFID 1999; Chester 2005; Cutter et al. 2006; Fordham 2011; Cannon 2015; Gaillard et al. 2017; World Bank Group 2017). Very few studies consider these additional intersectionalities with regard to people with disabilities.

\subsection{Differential Disparities}

People with disabilities are not a homogenous group, and therefore there are potential problems with disaster policies and procedures that do not include people with varying disabilities during disaster planning. The different abilities within the collective people with disabilities may lead to differential disparities in preparedness, response, recovery, and mitigation efforts. Inequities were found during disasters, not only towards the deaf community but also among different groups in the deaf community (Pickering et al. 2017). Grant (2018) discussed the possibility of mental health disorders being left out of several worldwide initiatives that surround disaster risk reduction. How disaster risk reduction planning efforts are approached could be related to how disability is defined and perceived, such as the difference between the medical and social construction perspectives of disability. It could potentially lead to the variability in terms used to address people with disabilities in planning documents (Kailes and Enders 2007; Priestley and Hemingway 2007) and the types of technology leveraged to assist in disaster risk reduction efforts (Bennett et al. 2017).

Information and communication technologies in disaster management are strongly emphasized in the SFDRR, notably the importance of these technologies in understanding the risks (Ludwig and Mattedi 2018). To ensure proper use and accessibility, policies and procedures should consider the needs of different categories of users and receivers (UNISDR 2015). It is crucial to make disaster risk communications widely available and accessible (UNISDR 2015; Ludwig and Mattedi 2018); however, that requires considerations of the heterogeneous nature of people with disabilities. What may be accessible to individuals with one type of disability may not be for others. 
Many people with disabilities who are self-sufficient before a disaster, become disproportionately marginalized following a disaster. Quaill et al. (2019) performed a qualitative study of interviews to assess the factors influencing people with disabilities to prepare, take protective action, and recover following a tropical cyclone in Australia. They found that experience was personal and individual, which therefore suggests strategies should be individualized to target unique concerns for each person with a disability (Quaill et al. 2019). With regards to intersectionality among people with disabilities, there is evidence to suggest that they, too, are capable of building capacity and managing their own risk. Kharade et al. (2017) successfully designed and implemented an intervention strategy based on the differentiated instruction technique to teach visually impaired students about disaster risk management.

\section{Recommendations for Policy and Practice in Disaster Risk Reduction that Support Persons with Disabilities}

Each recommendation below may be more salient for some regions than for others, but is important to note as there are several countries not included in the selection of articles. For each of the topics discussed below, recommendations for policy, practice, or future research are provided. The recommendations are considerations for national (or local) level policies and practices.

\subsection{Definitions of Disasters and Disability}

Defining disasters is significant because it helps frame when disaster risk reduction strategies are implemented. The Sendai Framework focuses on the hazards that may cause a disaster, but these hazards may not always create what scholars outline as a "disaster." For example, the Fritz (1961) definition of a disaster used in this article allows for the possibility of a similar hazard becoming a disaster in one area but not another. Even if the disruption is identical, if a local area can respond and recover from the hazard, it may simply be an emergency (Fischer 2003; Quarantelli 2006). Additionally, for areas prone to hazards that often only create emergencies, specific considerations for people with disability may not be included for actual disasters, especially if emergencies have not yet exacerbated significant marginalization of potentially vulnerable populations (Maini et al. 2017; Lunga et al. 2019). Therefore, the purposeful inclusion of a definition of a disaster is essential to policies, procedures, and planning for disaster risk reduction strategies.
Defining disability is equally important because it clarifies which populations are to be considered and included during disaster risk reduction planning. The studies reviewed highlighted the variation in definition and the models by which the descriptions are based (Grant 2018; Twigg et al. 2018; King et al. 2019). When viewed as a medical model, individuals with a disability are perceived as needing significant assistance and are treated as incapable of building their own capacity (Ronoh et al. 2015; Craig et al. 2019). When viewed through the lens of social construction theories, the possibility that people with disabilities can take charge of their own disaster risk management becomes possible. The definition of disability can have a significant impact on who is included as a critical stakeholder for risk reduction strategies. The definition can also have an influence on what strategies are adopted and how accommodations are proposed to enable accessibility throughout disaster risk reduction and management for all people with disabilities. Therefore, a purposeful definition of disability should also be included in disaster risk reduction strategies.

In addition to the impact on policy, how disability is understood can influence the practice of disaster risk reduction and management. As first responders, emergency planners, and voluntary organization leaders prepare for response and recovery efforts, how they understand vulnerability and disability leaves an impression, and could also have significant consequences for the people they seek to serve (Ronoh et al. 2015; Quaill et al. 2019; King et al. 2019; Lunga et al. 2019). Therefore, it is not enough to have a policy recommendation without a complementary practice recommendation.

- Policy Recommendation \#1: Purposeful inclusion of a definition of disaster

- Policy Recommendation \#2: Clear and purposeful definition of disability

- Practice Recommendation \#1: Comprehensive understanding of the social model of disability

\subsection{Intersectionality and Differential Disparities of Persons with Disabilities}

Individual human beings are difficult to group into one category alone, and our vulnerability is fluid. People may have more than one disability or are members of an additional group of individuals also face higher risk during a disaster. This intersectionality membership in multiple disability groups results in higher risk during disasters and can create overlapping vulnerabilities and compound marginalization (Banks 2018; Hernández-Saca et al. 2018). While most of the research on intersectionality is focused on employment, health, and education, there is the 
potential that intersectionality may be a factor in further marginalization during disasters. The research highlighted in this article suggests that children and older adults with disabilities, as well as individuals with a disability and specific health issues may not be included during the implementation of disaster risk reduction policies (Pickering et al. 2017; Grant 2018; Stough and Kelman 2018). Therefore, considerations of the potential intersectionality of vulnerability dimensions should be included in disaster risk reduction policies, procedures, and strategies as well (Bennett et al. 2017; Castro et al. 2017; Maini et al. 2017; Carby et al. 2018; Lunga et al. 2019).

The phrase "people with disabilities" does not refer to individuals with similar functions or needs. The term is used to describe diverse populations of individuals with potentially diverse abilities; therefore, a mosaic of accessibility considerations is necessary. Concerns for people with disabilities that only include accommodations for physical disability are not fully inclusive. Research shows that mental health diagnoses, which may consist of learning and cognitive disabilities, are often overlooked. Additionally, there is evidence that emergency communications may not appropriately consider the deaf community (Pickering et al. 2017; Bennett et al. 2018; Craig et al. 2019). Therefore, recognition of the differential impacts for various types of disability needs to be purposefully included in disaster risk reduction policies, procedures, and strategies. Additionally, persons with various disabilities should be included as stakeholders during planning and development.

- Policy Recommendation \#3: Consideration of intersectionality of vulnerability dimensions

- Policy Recommendation \#4: Recognition of the differential impacts for the various types of disability

\subsection{Enhancing the Disaster Preparedness of Persons with Disabilities}

Defining disability and understanding intersectionality may enable both concepts to influence how the SFDRR is implemented. Each of these factors contributes to how policymakers and practitioners perceive the ability to build the DRR capacity of persons with disabilities. The better individuals with a disability can understand and manage their risk during disasters, the more they can reduce their vulnerability to disasters. Empowerment is the key to this process, but is directly related to how these groups are defined and understood. Research shows there are few studies that examine practices to enhance disaster preparedness specifically for people with disabilities. Therefore, more empirical studies are needed to examine capacity building efforts among people with disabilities for all disaster risk reduction and management initiatives.

Research may highlight the various techniques by which the community can build capacity, but disaster practitioners, first responders, voluntary organizations, and community leaders need to empower people with disabilities. The flexibility and improvisation necessary for disaster management are not just because of the dynamic nature of various hazards; they are also due to the varied capacity of the individuals and communities impacted. Further marginalization occurs when efforts toward self-sufficiency and independence are depreciated and diminished. Therefore, understanding the necessity of and facilitation for independence and autonomy among people with disabilities is also vital to the enhancement of disaster preparedness.

- Research Recommendation \#1: Capacity building among people with disabilities during disasters

- Practice Recommendation \#2: Necessity of and facilitation for independence and self-sufficiency

\subsection{Cultural Attitudes toward Persons with Disabilities}

Often not addressed are the macro-level problems that influence the development and process of disaster planning initiatives. World-wide the attitudes about people with disabilities are not the same. The cultural perceptions of what is a disability and what it means to have a disability directly affect how disability may be nationally defined, and influence the perception of the capability for building capacity. Negative cultural attitudes also correlate to potential discrimination at the individual or institutional level. Very few studies have focused on how cultural perspectives of disability have influenced disaster risk reduction planning (Davis et al. 2013; Kelman and Stough 2015; Stough and Kelman 2018; King et al. 2019; Lunga et al. 2019).

Similarly, disaster practitioners need to be aware of how their attitudes and biases increase the vulnerability of people with disabilities and other marginalized populations. Given the potential for intersectionality among various dimensions of vulnerability, all biases, misconceptions, prejudices, and discriminatory practices will cause undue and unnecessary difficulties. There needs to be a deliberate and persistent acknowledgment and understanding of the consequences of improper perceptions.

- Research Recommendation \#2: Cultural attitudes towards people with disabilities in disaster risk reduction planning 
- Practice Recommendation \#3: Acknowledgement of cultural attitudes and biases, which may increase the difficulty for people with disability

\subsection{Investments in Disaster Risk Reduction}

Nearly all of the research reviewed in this article touched on the importance of investing in strategies to include people with disabilities in disaster risk reduction. Very few studies detailed the economic, social, health, and cultural resilience enhancements needed by people with disabilities and their environment. Empirical studies investigating the different investments made in a country, as well as their effectiveness, could transform how disaster preparedness is enhanced and could potentially alter the cultural attitudes of entire countries.

There are national and regional differences in terms of the type of disasters causing the most significant disruptions or marginalization of persons with disabilities. Much can be learned from the implementation strategies used and their impact. Further studies could explore how investments in disaster risk reduction strategies for people with disabilities compare by country or regionally.

- Research Recommendation \#3: Investments in disaster risk reduction for people with disability

- Research Recommendation \#4: Global policy analysis comparisons on the implementation of the SFDRR

\section{Conclusion}

Assessing the impacts of the SFDRR since inception shows clear areas for consideration with regards to enhancing human, social, and economic capital for people with disabilities. By all accounts, the SFDRR is a giant leap in the right direction towards proper inclusion of vulnerable populations. Though not nearly conclusive, the findings of this review highlight the need for further discussion on the advances in disaster risk reduction policy, enhancements for practice in the field, and investigations for future research, as well as the interpretation and implementation of the SFDRR at the nation-state level. Regional studies across the spectra of disaster and disability suggest the potential for several overlapping factors likely responsible for the variability in the implementation of the framework. Given the varied findings in this review resiliency is impacted globally by national and local (1) definitions of both disasters and disability; (2) understanding of intersectionality of vulnerabilities; (3) cultural attitudes about individuals with a disability; (4) building capacity in disaster preparedness; and (5) investments in risk reduction policies for people with disabilities.

Open Access This article is licensed under a Creative Commons Attribution 4.0 International License, which permits use, sharing, adaptation, distribution and reproduction in any medium or format, as long as you give appropriate credit to the original author(s) and the source, provide a link to the Creative Commons licence, and indicate if changes were made. The images or other third party material in this article are included in the article's Creative Commons licence, unless indicated otherwise in a credit line to the material. If material is not included in the article's Creative Commons licence and your intended use is not permitted by statutory regulation or exceeds the permitted use, you will need to obtain permission directly from the copyright holder. To view a copy of this licence, visit http://creativecommons. org/licenses/by/4.0/.

\section{References}

Akanuma, K., K. Nakamura, K. Meguro, M. Chiba, S.R. Gutiérrez Ubeda, K. Kumai, Y. Kato, J. Oonuma, et al. 2016. Disturbed social recognition and impaired risk judgment in older residents with mild cognitive impairment after the Great East Japan Earthquake of 2011: The Tome Project. Psychogeriatrics 16(6): 349-354.

Australia Government, Department of Home Affairs. 2018. National disaster risk reduction framework. https://www.homeaffairs.gov. $\mathrm{au} /$ emergency/files/national-disaster-risk-reduction-framework. pdf. Accessed 29 Jan 2020.

Baker, S., M. Reeve, M. Marella, D. Roubin, N. Caleb, and T. Brown. 2017. Experiences of people with disabilities during and after Tropical Cyclone Pam and recommendations for humanitarian leaders. In Proceedings of 1 st Asia Pacific humanitarian leadership conference, 26-28 April 2017, 70-78. Melbourne, Australia.

Banks, J. 2018. Invisible man: Examining the intersectionality of disability, race, and gender in an urban community. Disability \& Society 33(6): 894-908.

Bennett, D. 2010. State emergency plans: Assessing the inclusiveness of vulnerable populations. International Journal of Emergency Management 7(1). https://doi.org/10.1504/ijem.2010.032048.

Bennett, D., S. Laforce, C. Touzet, and K. Chiodo. 2018. American sign language $\&$ emergency alerts: The relationship between language, disability and accessible emergency messaging. International Journal of Mass Emergencies and Disasters 36(1): 71-87.

Bennett, D., B.D. Phillips, and E. Davis. 2017. The future of accessibility in disaster conditions: How wireless technologies will transform the life cycle of emergency management. Futures 87: $122-132$.

Cannon, T. 2015. Disasters, climate change, and the significance of 'culture.' In Cultures and disasters: Understanding cultural framings in disaster risk reduction, ed. F. Krüger, G. Bankoff, T. Cannon, B. Orlowski, E. Lisa, and F. Schipper, 88-106. New York: Routledge.

Carby, B., and T. Ferguson. 2018. An exploratory study of disaster risk management information for persons with disabilities in the Caribbean: Provisions and gaps. Caribbean Quarterly 64(1): 57-78.

Carby, B., T. Ferguson, S.-L. Steele, and Z. Maiyaki. 2018. An exploration of inclusivity for persons with disabilities in disaster risk management planning at the national and local government 
levels in Jamaica. Disability Studies Quarterly 38(4): Article 5776.

Castro, C.P., J.P. Sarmiento, R. Edwards, G. Hoberman, and K. Wyndham. 2017. Disaster risk perception in urban contexts and for people with disabilities: Case study on the city of Iquique (Chile). Natural Hazards 86(1): 411-436.

Chester, D.K. 2005. Theology and disaster studies: The need for dialogue. Journal of Volcanology and Geothermal Research 146(1): 319-328.

Collins, P.H., and S. Bilge. 2016. Intersectionality. Cambridge, UK: Polity Press.

Craig, L., N. Craig, E. Calgaro, D. Dominey-Howes, and K. Johnson. 2019. People with disabilities: Becoming agents of change in disaster risk reduction. In Emerging voices in natural hazards research, ed. F. Rivera, 327-356. Cambridge: Elsevier.

Cutter, S.L., C.T. Emrich, J.T. Mitchell, B.J. Boruff, M. Gall, M.C. Schmidtlein, C.G. Burton, and G. Melton. 2006. The long road home: Race, class, and recovery from Hurricane Katrina. Environment: Science and Policy for Sustainable Development 48(2): 8-20.

Davis, E.A., R. Hansen, M. Kett, J. Mincin, and J. Twigg. 2013. Disability. In Social vulnerability to disasters, 2nd edn., ed. D. Thomas, B. Phillips, W. Lovekamp, and A. Fothergill, 199-233. Boca Raton, FL: CRC Press.

Department of State. 2015. Explanation of position of the United States for the Sendai framework for disaster risk reduction 2015-2030. As delivered by Wilson Sumner in Sendai Japan. US Mission to International Organizations in Geneva. https:// geneva.usmission.gov/2015/03/19/sendai-framework-for-disas ter-risk-reduction-2015-2030/. Accessed 29 Jan 2020.

DFID (Department for International Development). 1999. Sustainable livelihoods guidance. London: DFID. https://www.livelihoods. org. Accessed 26 Oct 2019.

Fischer, H. 2003. The sociology of disaster: Definitions, research questions, and measurements. International Journal of Mass Emergencies and Disasters 21(9): 91-108.

Fordham, M., S. Gupta, S. Akerkar, and M. Scharf. 2011. Leading resilient development: Grassroots women's priorities, practices, and innovations. New York: United Nations Development Programme (UNDP).

Fritz, C.E. 1961. Disasters. In Social problems, ed. K.R. Merton, and R. Nisbet, 651-694. New York: Harcourt, Brace, and World.

Gaillard, J.C., A. Gorman-Murray, and M. Fordham. 2017. Sexual and gender minorities in disaster. Gender, Place \& Culture 24(1): $18-26$.

Grant, C. 2018. Disaster preparedness to reduce anxiety and postdisaster stress. K4D helpdesk report. Brighton, UK: Institute of Development Studies.

Gray, L. 2017. Social determinants of health, disaster vulnerability, severe and morbid obesity in adults: Triple jeopardy? International Journal of Environmental Research and Public Health 14(12): Article 1452.

Hernández-Saca, D.I., L. Gutmann Kahn, and M.A. Cannon. 2018. Intersectionality dis/ability research: How dis/ability research in education engages intersectionality to uncover the multidimensional construction of dis/abled experiences. Review of Research in Education 42(1): 286-311.

Inter-Agency Standing Committee (IASC) Reference Group for Mental Health and Psychosocial Support in Emergency Settings. 2015. Nepal earthquakes 2015: Desk review of existing information with relevance to mental health and psychosocial support. Kathmandu, Nepal. https://interagencystandingcommit tee.org/system/files/20150622_nepal_earthquakes_mhpss_desk_ review_150619.pdf. Accessed 28 Mar 2020.

Kabir, N.I. 2016. A policies of inclusion and exclusion for the persons with disabilities (PWDs) interlinked with the climate change adaptation: Case study of Bangladesh. International Journal of Multicultural and Multireligious Understanding 3(4): 14-26.

Kailes, J.I., and A. Enders. 2007. Moving beyond "special needs": A function-based framework for emergency management and planning. Journal of Disability Policy Studies 17(4): 230-237.

Kharade, K., H. Ha, and A. Ubale. 2017. Empowering students with visual impairment to prepare for disasters via differentiated instruction technique: A case study in India. International Journal of Special Education 32(3): 567-585.

Kelman, I., and L.M. Stough. 2015. (Dis) Ability and (Dis) Aster. In Disability and disaster: Explorations and exchanges, ed. I. Kelman, and L.M. Stough, 3-14. London: Palgrave Macmillan.

Kendra, J., L. Clay, and K. Gill, K. 2018. Resilience and disasters. In The Handbook of disaster research, 2nd edn., ed. H. Rodriguez, B. Donner, and J. Trainor, 87-107. Cham: Springer.

King, J., N. Edwards, H. Watling, and S. Hair. 2019. Barriers to disability-inclusive disaster management in the Solomon Islands: Perspectives of people with disability. International Journal of Disaster Risk Reduction 34: 459-466.

Ludwig, L., and M.A. Mattedi. 2018. The information and communication technologies in the risk management of social and environmental disasters. Ambiente \& Sociedade 21. https://doi. org/10.1590/1809-4422asoc0103r4vu1811ao.

Lunga, W., P.P. Bongo, D. van Niekerk, and C. Musarurwa. 2019. Disability and disaster risk reduction as an incongruent matrix: Lessons from rural Zimbabwe. Jàmbá: Journal of Disaster Risk Studies 11(1): 1-7.

Maini, R., L. Clarke, K. Blanchard, and V. Murray. 2017. The Sendai framework for disaster risk reduction and its indicators-Where does health fit in? International Journal of Disaster Risk Science 8(2): 150-155.

Malpass, A., C. West, J. Quaill, and R. Barker. 2019. Experiences of individuals with disabilities sheltering during natural disasters: An integrative review. Australian Journal of Emergency Management 34(2): 60-65.

Mileti, D. 1999. Disasters by design: A reassessment of natural hazards in the United States. Washington, DC: Joseph Henry Press.

Mizutori, M. 2018. Economic losses and displacement should drive disaster risk reduction efforts. UN Chronicle 55(2): 30-31.

Morrow, B.H. 1999. Identifying and mapping community vulnerability. Disasters 23(1): 1-18.

Mt. Kenya Times. 2016. Humanitarian partnership conference focuses on inclusive practices Nairobi on 21-22 September. https:// www.mtkenyatimes.co.ke/humanitarian-partnership-conferencefocuses-on-inclusive-practices/. Accessed 1 Apr 2020.

New Zealand. Ministry of Civil Defence \& Emergency Management. 2015. The guide to the national civil defence emergency management plan. https://www.civildefence.govt.nz/assets/ guide-to-the-national-cdem-plan/Guide-to-the-National-CDEMPlan-2015.pdf. Accessed 29 Jan 2020.

Perry, R. 2018. Defining disasters: An evolving concept. In The Handbook of disaster research, 2nd edn., ed. H. Rodriguez, W. Donner, J.E. Trainor, 3-22. New York: Springer.

Phibbs, S., C. Kenney, C. Severinsen, J. Mitchell, and R. Hughes. 2016. Synergising public health concepts with the Sendai framework for disaster risk reduction: A conceptual glossary. International Journal of Environmental Research and Public Health 13(12): Article 1241.

Philippines. National Disaster Risk Reduction and Management Council. 2011. The National Disaster Risk Reduction and Management Plan (NDRRMP). https://www.dilg.gov.ph/PDF_ File/reports_resources/DILG-Resources-2012116-420ac59e31. pdf. Accessed 29 Jan 2020.

Pickering, C.J., T. O'Sullivan, M. Genereux, M. David, M. Roy, G. Petit, D. Lane, and V. Bournival. 2017. Capability and 
vulnerability: A discourse analysis of multi-jurisdictional emergency planning documents. Prehospital and Disaster Medicine 32(S1): S182-S183.

Priestley, M., and L. Hemingway. 2007. Disability and disaster recovery: A tale of two cities? Journal of Social Work in Disability \& Rehabilitation 5(3-4): 23-42.

Quaill, J., R. Barker, and C. West. 2019. Experiences of individuals with physical disabilities before, during, and after tropical cyclones in Queensland, Australia. International Journal of Disaster Risk Reduction 39: Article 101122. https://doi.org/10. 1016/j.ijdrr.2019.101122.

Quarantelli, E.L. 2006. Catastrophes are different from disasters: Some implications for crisis planning and managing drawn from Katrina. http://understandingkatrina.ssrc.org. Accessed 28 Jan 2020.

Ronoh, S. 2017. Disability through an inclusive lens: Disaster risk reduction in schools. Disaster Prevention and Management: An International Journal 26(1): 105-119.

Ronoh, S., J.C. Gaillard, and J. Marlowe. 2015. Children with disabilities and disaster preparedness: A case study of Christchurch. Kōtuitui: New Zealand Journal of Social Sciences Online 10(2): 91-102.

Saunders, W., S. Kelly, S. Paisley, and L. Clarke. 2020. Progress toward implementing the Sendai Framework, the Paris Agreement, and the Sustainable Development Goals: Policy from Aotearoa New Zealand. International Journal of Disaster Risk Science 11(2). https://doi.org/10.1007/s13753-020-00269-8.

Stough, L.M., and D. Kang. 2015. The Sendai framework for disaster risk reduction and persons with disabilities. International Journal of Disaster Risk Science 6(2): 140-149.

Stough, L.M., and I. Kelman. 2018. People with disabilities and disasters. In Handbook of Disaster Research, ed. H. Rodríguez, W. Donner, and J.E. Trainor, 225-242. Cham: Springer.

Stough, L.M., E.M. Ducy, and D. Kang. 2017. Addressing the needs of children with disabilities experiencing disaster or terrorism. Current Psychiatry Reports 19(4): Article 24.

Thailand. National Disaster Prevention and Mitigation Committee. 2015. National disaster risk management plan. http://www. disaster.go.th/upload/download/file_attach/584115d64fcee.pdf. Accessed 29 Jan 2020.
Twigg, J., M. Kett, and E. Lovell. 2018. Disability inclusion and disaster risk reduction. Briefing Note. London: Overseas Development Institute. https://www.odi.org/sites/odi.org.uk/files/ resource-documents/12324.pdf. Accessed 26 Oct 2019.

UNISDR (United Nations Office for Disaster Risk Reduction). 2005. Hyogo framework for action 2005-2015: Building the resilience of nations and communities to disasters. Geneve: UNISDR.

UNISDR (United Nations Office for Disaster Risk Reduction). 2015. Sendai framework for disaster risk reduction, 2015-2030. https:// www.unisdr.org/we/inform/publications/43291. Accessed 30 Oct 2019.

United States. Department of Homeland Security. 2019. National Response Framework, 4th edn. https://www.fema.gov/medialibrary/assets/documents/117791. Accessed 29 Jan 2020.

Vanuatu. Ministry of Climate Change Adaptation. 2017a. SANMA provincial disaster response \& climate change management plan. http://www.ndmo.gov.vu/resources/downloads/category/19-disas ter-response-plans. Accessed 29 Jan 2020.

Vanuatu. Ministry of Climate Change Adaptation. 2017b. TAFEA provincial disaster response \& climate change management plan. http://www.ndmo.gov.vu/resources/downloads/category/19-disas ter-response-plans. Accessed 29 Jan 2020.

Vanuatu. Ministry of Climate Change Adaptation. 2019. National cyclone support plan 2019-2020. http://www.ndmo.gov.vu/ resources/downloads/category/19-disaster-response-plans. Accessed 29 Jan 2020.

Wisner, B., P. Blaikie, T. Cannon, and I. Davis. 2004. At risk: Natural hazards, people's vulnerability, and disasters. New York: Routledge.

World Bank. 2019. Disability and inclusion overview. Topics: Understanding poverty. https://www.worldbank.org/en/topic/dis ability. Accessed 30 Jan 2020.

World Bank Group. 2017. Disability inclusion in disaster risk management: Promising practices and opportunities for enhanced engagement. Washington, DC: Global Facility for Disaster Reduction and Recovery.

Wright, N., L. Fagan, J.M. Lapitan, R. Kayano, J. Abrahams, Q. Huda, and V. Murray. 2020. Health emergency and disaster risk management: Five years into implementation of the Sendai Framework. International Journal of Disaster Risk Science 11(2). https://doi.org/10.1007/s13753-020-00274-x. 